\title{
Antihyperglycaemic activity of Asparagus racemosus roots is partly mediated by inhibition of carbohydrate digestion and absorption, and enhancement of cellular insulin action
}

\author{
J. M. A. Hannan ${ }^{1}$, Liaquat Ali $^{2}$, Junaida Khaleque ${ }^{1}$, Masfida Akhter $^{2}$, Peter R. Flatt ${ }^{3}$ \\ and Yasser H. A. Abdel-Wahab ${ }^{3 *}$ \\ ${ }^{1}$ Department of Pharmacy, North South University, Dhaka, Bangladesh \\ ${ }^{2}$ Research Division, BIRDEM, Dhaka, Bangladesh \\ ${ }^{3}$ SAAD Centre for Pharmacy and Diabetes, School of Biomedical Sciences, University of Ulster, Coleraine, Northern Ireland \\ BT52 1SA, UK \\ (Submitted 8 December 2010 - Final revision received 31 May 2011 - Accepted 6 July 2011 - First published online 8 September 2011)
}

\begin{abstract}
Asparagus racemosus roots have been shown to enhance insulin secretion in perfused pancreas and isolated islets. The present study investigated the effects of ethanol extracts of $A$. racemosus roots on glucose homeostasis in diabetic rats, together with the effects on insulin action in 3T3 adipocytes. When administered orally together with glucose, A. racemosus extract improved glucose tolerance in normal as well as in two types of diabetic rats. To investigate the possible effects on carbohydrate absorption, the sucrose content of the gastrointestinal tract was examined in $12 \mathrm{~h}$ fasted rats after an oral sucrose load $(2.5 \mathrm{~g} / \mathrm{kg}$ body weight). The extract significantly suppressed postprandial hyperglycaemia after sucrose ingestion and reversibly increased unabsorbed sucrose content throughout the gut. The extract also significantly inhibited the absorption of glucose during in situ gut perfusion with glucose. Furthermore, the extract enhanced glucose transport and insulin action in 3T3-L1 adipocytes. Daily administration of $A$. racemosus to type 2 diabetic rats for $28 \mathrm{~d}$ decreased serum glucose, increased pancreatic insulin, plasma insulin, liver glycogen and total oxidant status. These findings indicate that antihyperglycaemic activity of $A$. racemosus is partly mediated by inhibition of carbohydrate digestion and absorption, together with enhancement of insulin secretion and action in the peripheral tissue. Asparagus racemosus may be useful as a source of novel antidiabetic compounds or a dietary adjunct for the management of diabetes.
\end{abstract}

Key words: Asparagus racemosus: Diabetes mellitus: Carbohydrate digestion and absorption: Gastrointestinal motility: Liver glycogen: Glucose uptake: Insulin

Asparagus racemosus (Liliaceae), locally known as Shatavari, is available throughout India, Asia, Australia and Africa. Asparagus is a popular vegetable consumed in many parts of the world. The shoots, the edible part of the plant, are frequently used in salads, vegetable dishes and soups. In India, asparagus is used mainly for its medicinal properties in the treatment of diarrhoea, dysentery, rheumatism and nervous breakdown ${ }^{(1,2)}$. Studies on crude extracts and isolated components have revealed a wide range of biological activities, such as anti-tumour ${ }^{(3)}$, antifungal ${ }^{(4)}$, anti-mutagenic ${ }^{(5)}$, immunostimulatory $^{(6-8)}$ and diuretic ${ }^{(9)}$ properties. Asparagus also has been used as a lactogogue in lactational inadequacy $^{(10)}$ and appears to help in the prevention and management of post-operative adhesions ${ }^{(7)}$. Extracts exerted potent antioxidant properties on liver mitochondrial membranes in vitro ${ }^{(11)}$. The chemical constituents of $A$. racemosus have been studied, revealing flavonoids, oligosaccharides, amino acids, sulphur-containing acids and steroidal saponins ${ }^{(3)}$. Various reports have suggested that polysaccharides from A. racemosus exhibit potent antioxidant as well as radioprotective properties ${ }^{(12,13-15)}$.

It has been reported that asparagus decreased gastric emptying ${ }^{(16)}$, whereas other studies have shown that methanolic root extract decreased intestinal propulsive movement, castor oil-induced diarrhoea and intestinal fluid accumulation in rats. Yohimbine, an $\alpha_{2}$-adrenoceptor blocker, attenuated the anti-diarrhoeal effect of the extract ${ }^{(17)}$. A. racemosus reversed the effects of cisplatin on gastric emptying and normalised cisplatin-induced intestinal hypermotility ${ }^{(18)}$.

The root of asparagus has been claimed to possess antidiabetic properties by traditional healers. It has been reported that $A$. racemosus reduced blood glucose in rats ${ }^{(19)}$

Abbreviation: GI, gastrointestinal.

*Corresponding author: Dr Y. H. Abdel-Wahab, fax + 442870 324965, email y.abdel-wahab@ulster.ac.uk 
and rabbits ${ }^{(20)}$. Furthermore, recent studies have demonstrated that the extract of $A$. racemosus roots enhanced insulin secretion from perfused pancreas, isolated islets and clonal pancreatic $\beta$-cells ${ }^{(21)}$. These studies have revealed that the ethanol extract and each of the hexane, chloroform and ethyl acetate partition fractions of $A$. racemosus concentration-dependently stimulated insulin secretion ${ }^{(21)}$. Furthermore, the stimulatory effects were potentiated by glucose, 3-isobutyl-1-methyl xanthine, tolbutamide and a depolarising concentration of $\mathrm{KCl}$, indicating that the insulin-releasing machinery of $\beta$-cells has been triggered through specific secretory pathways ${ }^{(21)}$. These findings reveal that constituents of $A$. racemosus root extracts have wide-ranging stimulatory effects on physiological insulinotropic pathways.

The aim of the present study was to further evaluate the hypoglycaemic effects of $A$. racemosus in animal models of diabetes and to examine the possible effects on intestinal glucose absorption, gastrointestinal (GI) motility and cellular glucose uptake.

\section{Materials and methods}

\section{Plant material and preparation of extract}

Roots of $A$. racemosus were purchased from Ramkrishna Mission (Kolkata, India) and botanically authenticated, and voucher specimens were deposited in the National Herbarium (Bangladesh). The roots were dried at $40^{\circ} \mathrm{C}$ and ground into a fine powder (200 mesh) by a cyclotec-grinding machine. The powder $(2 \mathrm{~kg}$ ) was extracted with $80 \%$ ethanol (10 litres) in a stainless-steel extraction tank for approximately $4 \mathrm{~d}$ at room temperature by changing ethanol daily. The combined extract was filtered and evaporated to dryness using a rotary evaporator. A membrane pump was used to evacuate the extract in order to remove the residual solvent. The extract was then freeze-dried (275 g) using a Varian 801 LY-3-TT freezedryer (Varian, Lexington, MA, USA). The dry sample was stored at $4^{\circ} \mathrm{C}$.

\section{Experimental animals and induction of diabetes}

Long-Evans male rats (180-220 g body weight) bred at the Bangladesh Institute of Research and Rehabilitation in Diabetes, Endocrine and Metabolic Disorders animal house (Dhaka, Bangladesh) were used in the study. Rats were maintained at a constant room temperature of $22 \pm 5^{\circ} \mathrm{C}$ with a humidity of $40-70 \%$ and a $12 \mathrm{~h}$ light $-12 \mathrm{~h}$ dark cycle. A standard pellet diet and water were supplied ad libitum. The overall nutrient composition of the diet was $36.2 \%$ carbohydrate, $20.9 \%$ protein, $4.4 \%$ fat and $38.5 \%$ fibre, with a metabolisable energy content of $11.8 \mathrm{MJ} / \mathrm{kg}$ (2820 kcal $/ \mathrm{kg})$. Insulin-dependent (type 1-like) diabetes was induced by a single intraperitoneal injection of streptozotocin $(65 \mathrm{mg} / \mathrm{kg}$ body weight, freshly dissolved in $0.5 \mathrm{M}$-citrate buffer, $\mathrm{pH} 4.5)$ to $12 \mathrm{~h}$ fasted rats $(180-220 \mathrm{~g})$. Blood glucose level was checked $7 \mathrm{~d}$ after streptozotocin administration. Animals having blood glucose levels $>20 \mathrm{mmol} / 1$ were considered to have diabetes. Diabetes representing type 2 was induced by a single intraperitoneal injection of 48-h-old rats with $90 \mathrm{mg}$ streptozotocin/ $\mathrm{kg}$ body weight ${ }^{(22)}$. The experiments were carried out for 3 months after streptozotocin injection. Rats having a blood glucose level of $8-9 \mathrm{mmol} / \mathrm{l}$ at fasting and $10 \mathrm{mmol} / \mathrm{l}$ and above after the glucose load were taken as type 2 diabetic model rats for the experiments. All experiments involving animals were conducted according to the UK Home Office regulations (UK Animals Scientific Procedures Act 1986) and the 'Principles of Laboratory Animal Care' (National Institutes of Health publication no. 86-23, revised 1985).

\section{Acute and chronic effects of plant extract on glucose homeostasis}

To study the acute effects of $A$. racemosus on basal blood glucose, the ethanol extract was administered orally $(1.25 \mathrm{~g} / \mathrm{kg}$ body weight) to $12 \mathrm{~h}$ fasted non-diabetic, type 1 and type 2 diabetic rats. Toxicity tests were carried out on ethanol extracts of $A$. racemosus and did not have any harmful effects in rats including histology of liver, kidney, pancreas, stomach and lungs. The control group received an equal volume of deionised water $(10 \mathrm{ml} / \mathrm{kg})$. In another set of experiments, the extract was similarly administered together to the three groups of rats with glucose $(2.5 \mathrm{~g} / \mathrm{kg}$ body weight). Controls received glucose only. To evaluate the long-term effects of $A$. racemosus on glucose homeostasis, the extract $(1.25 \mathrm{~g} / \mathrm{kg}$ body weight) was administered to type 2 diabetic rats by oral administration twice daily for $28 \mathrm{~d}$. Control rats received an equal dose of water. Blood samples were collected and serum was separated by centrifugation and stored at $-20^{\circ} \mathrm{C}$ until measurement of different biochemical tests.

\section{Effect of plant extract on residual gut sucrose content}

The effects of $A$. racemosus on sucrose absorption from the gut were determined by the measurement of unabsorbed sucrose content after an oral sucrose load. Non-diabetic and type 2 diabetic rats, fasted for $12 \mathrm{~h}$, received a $50 \%$ sucrose solution by oral administration $(2.5 \mathrm{~g} / \mathrm{kg}$ body weight) with or without ethanol extract of $A$. racemosus $(1.25 \mathrm{~g} / \mathrm{kg}$ body weight). Blood samples were obtained from the tail vein before and at 30, 60, 120 and $240 \mathrm{~min}$ after the sucrose load for the determination of glucose. Some of the rats were killed at the same timings for the determination of unabsorbed sucrose contents of the GI tract. The GI tract was excised and divided into six segments: the stomach, the upper $20 \mathrm{~cm}$, middle and lower $20 \mathrm{~cm}$ of the small intestine, the caecum and the large intestine. Each segment was washed with acidified ice-cold saline and centrifuged at $3000 \mathrm{rpm}(1000 \mathrm{~g}$ ) for $10 \mathrm{~min}$. The resulting supernatant was boiled for $2 \mathrm{~h}$ to hydrolyse sucrose followed by the neutralisation of the solution with $\mathrm{NaOH}$. Blood glucose concentrations and the amount of glucose liberated from residual sucrose in the GI tract were measured. GI sucrose content was calculated from the amount of liberated glucose ${ }^{(23)}$. 


\section{Plant extract effect on intestinal glucose absorption}

An in situ intestinal perfusion technique ${ }^{(24)}$ was used to evaluate the effect of $A$. racemosus on intestinal absorption of glucose in normal rats fasted for $36 \mathrm{~h}$ and anaesthetised with sodium pentobarbital ( $50 \mathrm{~g} / \mathrm{kg}$ body weight). The extract of $A$. racemosus $(25 \mathrm{mg} / \mathrm{ml})$, equivalent to $1.25 \mathrm{~g} / \mathrm{kg}$, suspended in KrebsRinger buffer, supplemented with glucose $(54 \mathrm{~g} / \mathrm{l})$, was passed through the pylorus and the perfusate was collected from a catheter inserted at the end of the ileum. The control group was perfused only with Krebs' solution supplemented with glucose. Perfusion was carried out at a constant rate of $0.5 \mathrm{ml} / \mathrm{min}$ for $30 \mathrm{~min}$ at $37^{\circ} \mathrm{C}$. The results are expressed as a percentage of absorbed glucose, calculated from the amount of glucose in solution before and after the perfusion.

\section{Effects of extract on intestinal disaccharidase activity and gastrointestinal motility}

The extract $(1.25 \mathrm{~g} / \mathrm{kg}$ body weight) was fed orally to $24 \mathrm{~h}$ fasted normal rats. The control group was administered with an equal volume of water. After $60 \mathrm{~min}$, rats were killed and the small intestine was isolated, cut longitudinally, rinsed with ice-cold saline and homogenised in $10 \mathrm{ml}$ saline (0.9\% $\mathrm{NaCl}$ ). Aliquots of the homogenate were then incubated with $40 \mathrm{~mm}$-sucrose at $37^{\circ} \mathrm{C}$ for $60 \mathrm{~min}$. The converted glucose in the solution and protein of the homogenate were determined. Disaccharidase activity was calculated from the glucose concentration converted from sucrose as $\mu \mathrm{mol} / \mathrm{mg}$ protein per $h$.

GI motility was evaluated using $\mathrm{BaSO}_{4}$ milk as described previously by Chatterjee ${ }^{(25)}$. $\mathrm{BaSO}_{4}$ milk was prepared by adding $\mathrm{BaSO}_{4}$ as $10 \%(\mathrm{w} / \mathrm{v})$ in $0.5 \%$ carboxy methyl cellulose suspension. The ethanol extract was administered orally at the dose of $1.25 \mathrm{~g} / \mathrm{kg}$ body weight $1 \mathrm{~h}$ before the oral administration of $\mathrm{BaSO}_{4}$ milk. Control rats received distilled water $(10 \mathrm{ml} / \mathrm{kg})$. Treated and control rats were killed $15 \mathrm{~min}$ after $\mathrm{BaSO}_{4}$ administration. The distance traversed by $\mathrm{BaSO}_{4}$ milk was measured and is expressed as a percentage of the total length of the small intestine (from the pylorus to the ileocaecal junction).

\section{Effects of extract on glucose uptake and insulin action}

3T3-L1 cells (ATCC, Manassas, VA, USA) were used to evaluate the effect of extract on glucose uptake and insulin action. 3T3L1 fibroblasts were cultured and differentiated into adipocytes according to the method described by Frost \& Lane ${ }^{(26)}$. Cell monolayers were washed and then incubated for $15 \mathrm{~min}$ at $37^{\circ} \mathrm{C}$ in Krebs-Ringer buffer supplemented with ethanol extract of $A$. racemosus and insulin, as indicated in Fig. 6. After $15 \mathrm{~min}$, glucose uptake was initiated, according to the established protocol of Frost \& Lane ${ }^{(26)}$, by the addition of $50 \mathrm{ml}$ tritiated 2-deoxyglucose $(18.5 \mathrm{MBq} /$ well) plus glucose ( $50 \mathrm{mmol} / \mathrm{l}$ final concentration). The experiment was terminated after $5 \mathrm{~min}$ by three rapid washes with ice-cold buffer, after which the cells were detached and lysed with $0 \cdot 1 \%$ SDS and subsequently lysed. Radioactivity was measured on a Wallac 1409 scintillation counter (Wallac, Turke, Finland) and glucose uptake is expressed as disintegrations per min.

\section{Analysis}

All samples were stored at $-20^{\circ} \mathrm{C}$ until analysis. Glucose was measured by the glucose-oxidase method, using kits from Sera Pak (Berkeley, CA, USA). Hepatic glycogen was determined by using the anthrone $\operatorname{method}^{(27)}$. Protein contents were determined using the detergent-compatible protein kit (Bio-Rad, Hercules, CA, USA). Total antioxidant status was determined using the ABTSw substrate assay kit according to the manufacturer's instructions (Sera Pak). Insulin was measured by ELISA using kits supplied by Crystal Chem, Inc. (Downers Grove, IL, USA) or RIA ${ }^{\text {(28). }}$.

\section{Statistical analysis}

Statistical analysis was performed using Statistical Package for Social Science software for Windows version 12 (SPSS, Inc., Chicago, IL, USA). Results are presented as means and standard deviations. Groups of data were compared using unpaired Student's $t$ test and the Mann-Whitney $U$ test, where appropriate. Where data were collected over a number of time points, analysis was based on repeatedmeasures ANOVA, with Bonferroni adjustment to ensure an overall error rate of $5 \%$. One-way ANOVA was performed and pairwise comparisons were made with the control group using Dunnett's test to preserve an overall error rate of $5 \%$. A two-tailed $P$ value of $<0.05$ was considered statistically significant.

\section{Results}

Acute and chronic effects of ethanol extract of Asparagus racemosus on glucose homeostasis

Oral administration of ethanol extract of $A$. racemosus did not show any hypoglycaemic effect in the fasting state in either normal, type 2 or type 1 diabetic rats (Fig. 1(a)-(c)). The extract improved glucose tolerance at $30 \mathrm{~min}(P<0.05$ and $<0 \cdot 01$, respectively) when fed simultaneously with glucose in normal and type 2 diabetes rats (Fig. 1(d)-(f)).

Administration of plant extract twice daily for $28 \mathrm{~d}$ to type 2 diabetic rats significantly lowered serum glucose levels $(P<0.01$; Table 1$)$. In addition, it increased serum insulin level by $30 \%$ compared with controls (Table 1 ). Total antioxidant status was significantly increased with the treatment of extract compared with the control group $(P<0 \cdot 01$; Table 1$)$. After chronic feeding of the extract, pancreatic insulin and liver glycogen content was increased significantly $(P<0.05)$ compared with control rats (Table 1).

\section{Effects of Asparagus racemosus on serum glucose after the sucrose load}

A peak serum glucose level for non-diabetic as well as type 2 diabetic rats was achieved $30 \mathrm{~min}$ after sucrose ingestion 
(Fig. 2). The rise in blood glucose after sucrose loading was suppressed by the administration of ethanol extract at $30 \mathrm{~min}$ $(P<0.05)$ and $60 \mathrm{~min}(P<0.05)$ in both normal and type 2 diabetic rats. This may reflect the positive effects of extract on insulin secretion/action but evidence for delayed absorption is provided by direct measurement of sucrose in the gut.

\section{Effects of Asparagus racemosus on unabsorbed sucrose content in the gut}

In non-diabetic rats, little carbohydrate was detected as liberated glucose in the GI tract after the $20 \mathrm{~h}$ fast (data not shown). After sucrose loading (average $425 \mathrm{mg} / \mathrm{rat}$ ), sucrose was detected in the stomach and the upper, middle and lower small intestine at $1 \mathrm{~h}$ as well as in the stomach, upper and middle intestine at $2 \mathrm{~h}$. However, at $4 \mathrm{~h}$, sucrose content was almost nil throughout the GI tract, indicating that sucrose was rapidly hydrolysed and absorbed in the upper part of the intestine (Fig. 3). The unabsorbed sucrose content after the administration of sucrose $(2.5 \mathrm{~g} / \mathrm{kg}$ body weight) with ethanol extract $(1.25 \mathrm{~g} / \mathrm{kg})$ was increased significantly $(P<0 \cdot 01)$ in the stomach, upper and middle intestine after $30 \mathrm{~min}$, in the upper and middle intestine after $1 \mathrm{~h}$ and in the middle and lower intestine after $2 \mathrm{~h}$. After $4 \mathrm{~h}$, sucrose was not detected in the gut of either group (Fig. 3).

After the administration of sucrose in type 2 diabetic rats, it remained in the stomach, upper, middle and lower small intestine at $1 \mathrm{~h}$ as well as in the stomach at $2 \mathrm{~h}$. This indicates that sucrose was more slowly absorbed in type 2 diabetic rats given the plant extract (Fig. 3).

When extract was administered to type 2 diabetic rats with the sucrose load, the residual sucrose content was increased significantly $(P<0.001)$ in the upper intestine after $30 \mathrm{~min}$, in the whole small intestine after $1 \mathrm{~h}$ and in the entire small intestine as well as in the caecum after $2 \mathrm{~h}$. After $4 \mathrm{~h}$, sucrose content were almost nil in the control group. However,
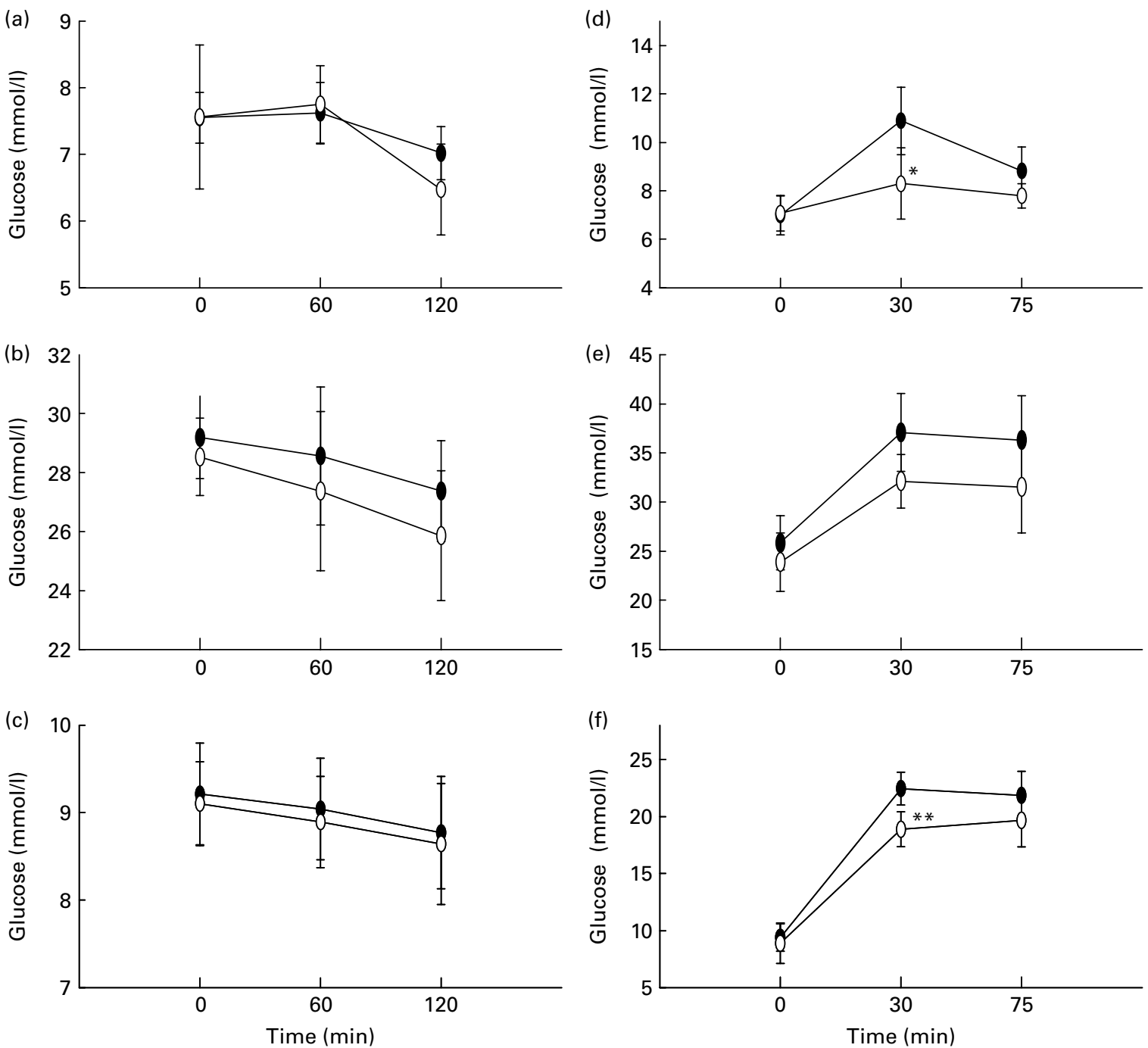

Fig. 1. Effects of ethanol extract of Asparagus racemosus (o) on (a-c) fasting and (d-e) glucose tolerance in (a, d) non-diabetic, (b, e) type 1 and (c, f) type 2 diabetic rats. Values are means and standard deviations represented by vertical bars $(n 6)$. Fasted rats were given ethanol extract by oral administration $\left(1.25 \mathrm{~g} / \mathrm{kg}\right.$ body weight) with or without glucose $\left(2.5 \mathrm{~g} / \mathrm{kg}\right.$ body weight). Mean values were significantly different from those of respective control $(\bullet)$ rats: ${ }^{\star} P<0.05$, ${ }^{\star \star} P<0.01$ (derived from repeated-measures ANOVA and adjusted using Bonferroni correction). 
Table 1. Effects of ethanol extract of Asparagus racemosust roots on serum levels of glucose and other parameters in type 2 diabetic rats after $28 \mathrm{~d}$ of feeding

(Mean values and standard deviations, $n 12$ )

\begin{tabular}{|c|c|c|c|c|c|c|c|c|}
\hline \multirow[b]{3}{*}{ Parameters } & \multicolumn{4}{|c|}{ Day 0} & \multicolumn{4}{|c|}{ Day 28} \\
\hline & \multicolumn{2}{|c|}{ Control } & \multicolumn{2}{|c|}{ A. racemosus } & \multicolumn{2}{|c|}{ Control } & \multicolumn{2}{|c|}{ A. racemosus } \\
\hline & Mean & SD & Mean & SD & Mean & $\mathrm{SD}$ & Mean & SD \\
\hline Glucose (mmol/l) & $8 \cdot 84$ & $1 \cdot 3$ & $9 \cdot 14$ & $1 \cdot 0$ & 8.90 & 1.0 & $6 \cdot 50^{\star \star}$ & 0.8 \\
\hline Insulin (ng/ml) & 0.434 & 0.1 & 0.454 & 0.1 & 0.442 & 0.1 & $0.579^{*}$ & 0.1 \\
\hline Pancreatic insulin (nmol/g pancreas) & & & & & 0.79 & 0.2 & $1.07^{\star}$ & 0.4 \\
\hline Liver glycogen ( $\mathrm{g} / 100 \mathrm{~g}$ tissue) & & & & & 1.69 & 0.4 & $2 \cdot 45^{\star}$ & 0.7 \\
\hline Total antioxidant status $(\mathrm{mmo} / \mathrm{l})$ & 0.87 & 0.1 & 0.91 & 0.1 & 0.89 & 0.1 & $1 \cdot 16^{\star \star}$ & 0.1 \\
\hline
\end{tabular}

Mean values were significantly different from those of type 2 diabetic control rats: ${ }^{\star} P<0.05,{ }^{\star \star} P<0.01$ (unpaired $t$ test).

$\dagger A$. racemosus was administered orally $(1.25 \mathrm{~g} / \mathrm{kg}$ body weight) twice daily for $28 \mathrm{~d}$.

‡ Diabetes was induced by a single intraperitoneal injection of $90 \mathrm{mg}$ streptozotocin $/ \mathrm{kg}$ to neonatal rats 3 months previously.

at this time, sucrose was detected in the lower intestine as well as in the caecum (Fig. 3).

\section{Effects of Asparagus racemosus on intestinal glucose absorption}

Intestinal glucose absorption was almost constant during $30 \mathrm{~min}$ of perfusion with glucose. The glucose solution when supplemented with the extract, intestinal glucose absorption was decreased significantly $(P<0.05$ to $P<0 \cdot 01)$ during most of the perfusion period (Fig. 4).

\section{Effects of Asparagus racemosus on intestinal disaccharidase activity and gastrointestinal motility}

The ethanol extract of $A$. racemosus inhibited disaccharidase (sucrose) activity significantly $(P<0.05)$ in normal rats. In contrast, the extract did not show any effect on GI motility (Fig. 5).

\section{Effects of ethanol extract of Asparagus racemosus on glucose uptake in 3T3-L1 cells}

Ethanol extract of $A$. racemosus significantly enhanced glucose uptake compared with the control (no insulin, $P<0.05)$. This effect was further increased by the presence of $10^{-9} \mathrm{M}$-insulin $(P<0.001$; Fig. 6).

\section{Discussion}

The present study was undertaken to assess antihyperglycaemic properties and the mechanism of action of $A$. racemosus. The findings show that the ethanol extract of $A$. racemosus roots elicited glucose-lowering effects in normal and type 2 diabetic rats when administered simultaneously with glucose. However, no significant effects were observed in type 1 diabetic rats. This indicates that the antihyperglycaemic effects of the active plant constituent(s) are partly mediated by improving the insulin secretory capacity of the $\beta$-cells ${ }^{(21)}$ or enhancing insulin action ${ }^{(29)}$. The former is consistent with increased serum and pancreatic insulin in $28 \mathrm{~d}$ chronic studies, whereas the latter accords with observations made with 3T3 adipocytes.
In acute experiments, when $A$. racemosus was administered simultaneously with glucose, significant glucose lowering was observed in non-diabetic as well as type 2 diabetic rats. In the postprandial state, this effect may partly result from interference with intestinal absorption of glucose ${ }^{(29)}$. Indeed, A. racemosus extract significantly inhibited glucose absorption during gut perfusion. In addition, postprandial hyperglycaemia was suppressed after sucrose ingestion and the amounts of unabsorbed sucrose were measured throughout the gut when
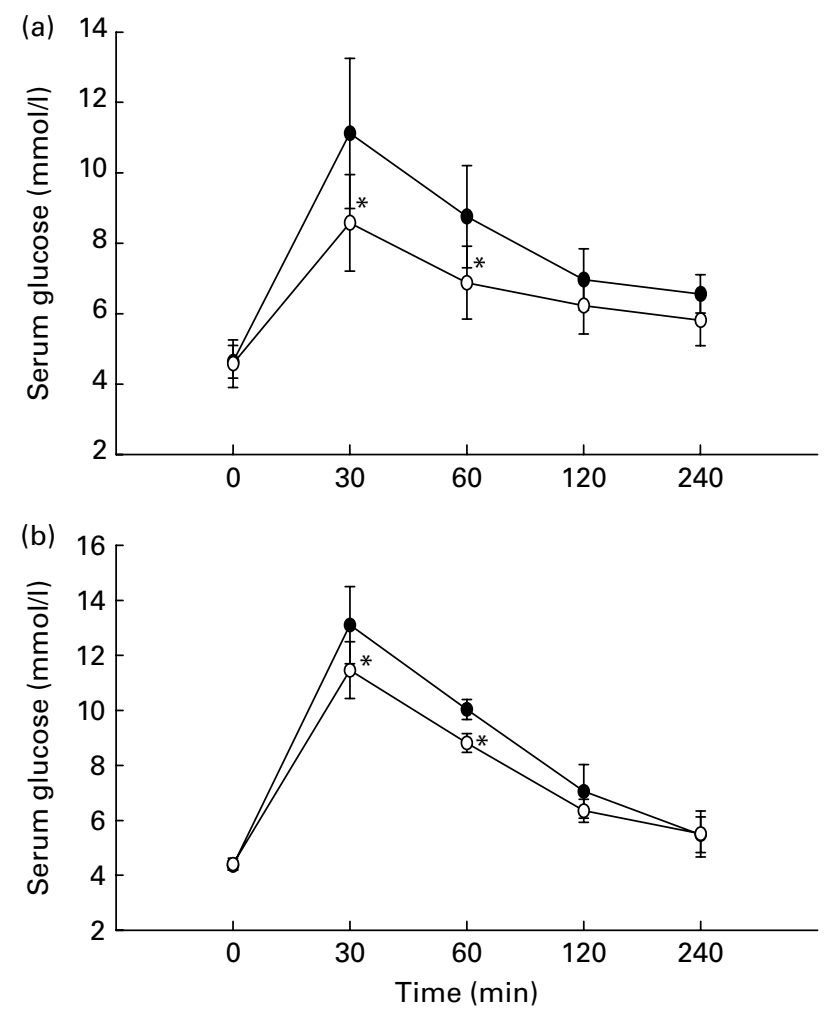

Fig. 2. Effects of ethanol extract of Asparagus racemosus (0) on serum glucose after the sucrose load in (a) non-diabetic and (b) type 2 diabetic rats. Rats were fasted for $20 \mathrm{~h}$ and administered orally with a sucrose solution $(2.5 \mathrm{~g} / \mathrm{kg}$ body weight) with or without ethanol extract $(1.25 \mathrm{~g} / \mathrm{kg}$ body weight). Values are means and standard deviations represented by vertical bars $(n 6)$. Mean values were significantly different from those of respective control ( $\bullet$ rats: ${ }^{\star} P<0.05$ (derived from repeated-measures ANOVA and adjusted using Bonferroni correction). 
(a)
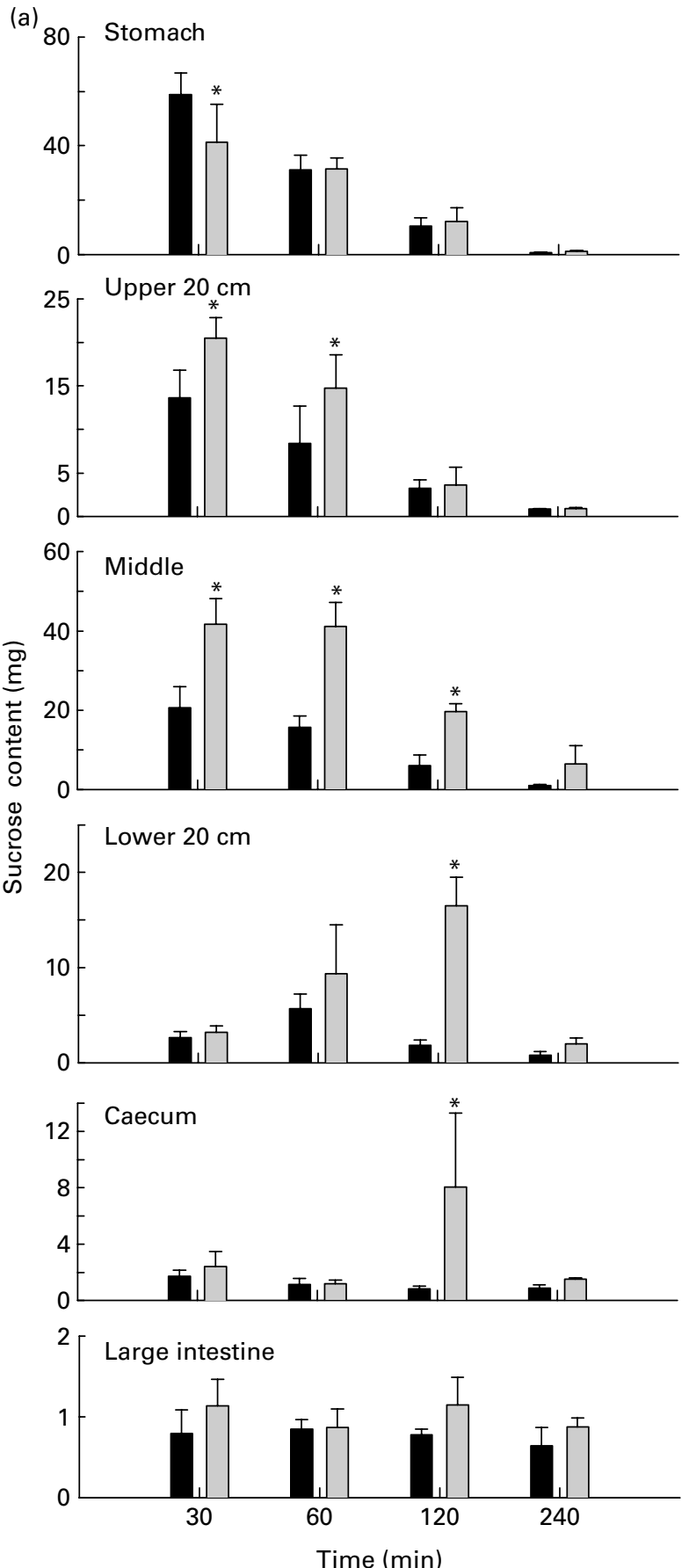

(b)
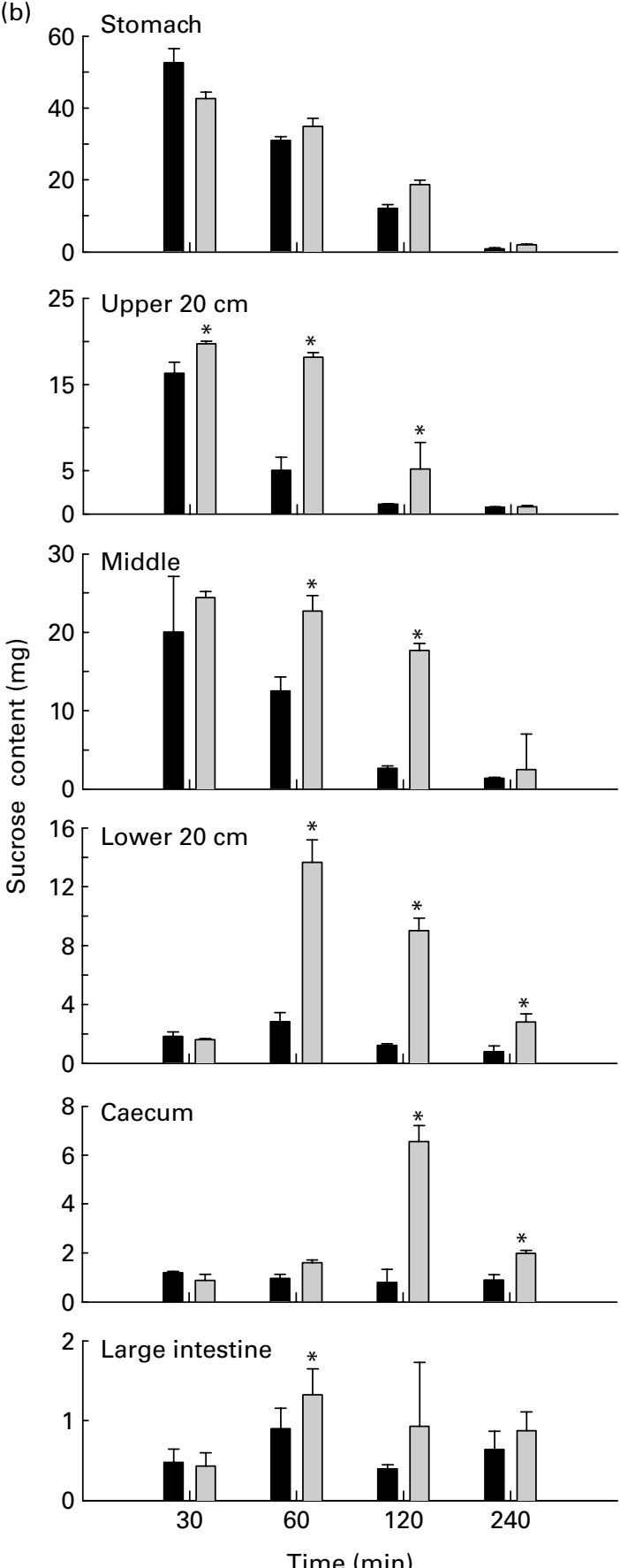

Fig. 3. Effects of ethanol extract of Asparagus racemosus ( $\square$ ) on gastrointestinal sucrose content after oral sucrose loading in (a) non-diabetic and (b) type 2 diabetic rats. Rats were fasted for $20 \mathrm{~h}$ before the oral administration of a sucrose solution $(2.5 \mathrm{~g} / \mathrm{kg}$ body weight) with or without ethanol extract ( $1.25 \mathrm{~g} / \mathrm{kg}$ body weight). Values are means and standard deviations represented by vertical bars $(n 6) .{ }^{*}$ Mean values were significantly different from those of control ( $\square$ ) rats $(P<0.05)$.

administered with $A$. racemosus. The extract also inhibited intestinal disaccharidase enzyme activity, which suggests that retardation of carbohydrate absorption was at least partially due to the inhibition of gut enzyme activity. However, further studies may be required to evaluate further such effect on animal models of diabetes. When GI motility was evaluated in non-diabetic rats under physiological conditions using $\mathrm{BaSO}_{4}$ milk as described previously by Chatterjee ${ }^{(25)}$ and expressed as a percentage of $\mathrm{BaSO}_{4}$ milk passed through from the total length of the small intestine (from the pylorus to the ileocaecal junction), the extract did not show any significant effect on the motility of the GI tract compared with the control. However, further studies may be required to evaluate the effects of $A$. racemosus on GI motility in diabetic models.

To further elucidate the possible mechanisms underlying the antihyperglycaemic effects of $A$. racemosus, studies of 


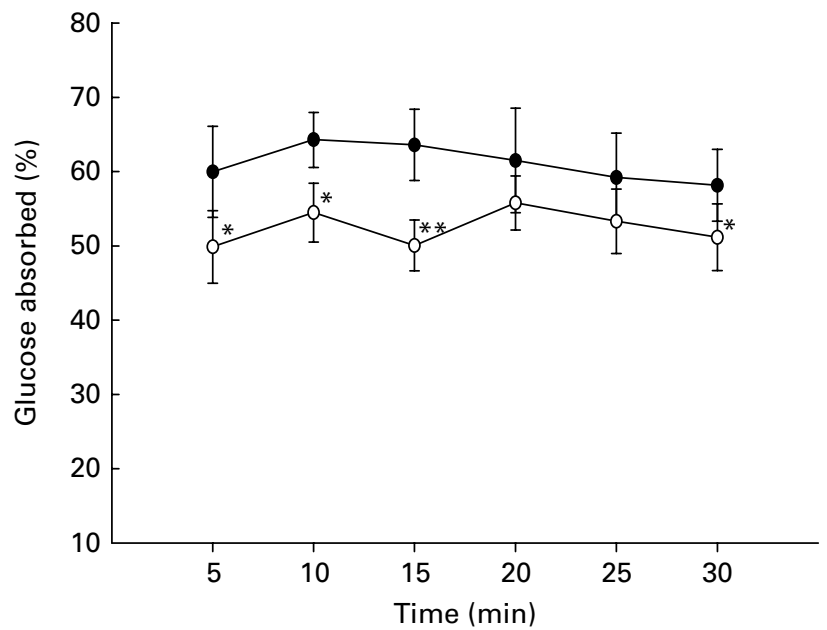

Fig. 4. Effects of ethanol extract of Asparagus racemosus (O) on intestinal glucose absorption in non-diabetic rats. Rats were fasted for $36 \mathrm{~h}$ and the intestine was perfused with glucose $(54 \mathrm{~g} / \mathrm{l})$ with or without ethanol extract of A. racemosus $(25 \mathrm{mg} / \mathrm{ml})$. Values are means and standard deviations represented by vertical bars $(n 6)$. Mean values were significantly different from those of respective control $(\bullet)$ rats: ${ }^{\star} P<0.05$, ${ }^{\star \star} P<0.01$ (derived from repeated-measures ANOVA and adjusted using Bonferroni correction).

glucose uptake by 3T3-L1 cells were performed. These revealed that ethanol extract significantly enhanced glucose transport with further stimulation in the presence of $10^{-9} \mathrm{M}$-insulin. These results suggest that actions of the plant extract on glucose transport may be achieved, to some extent, without
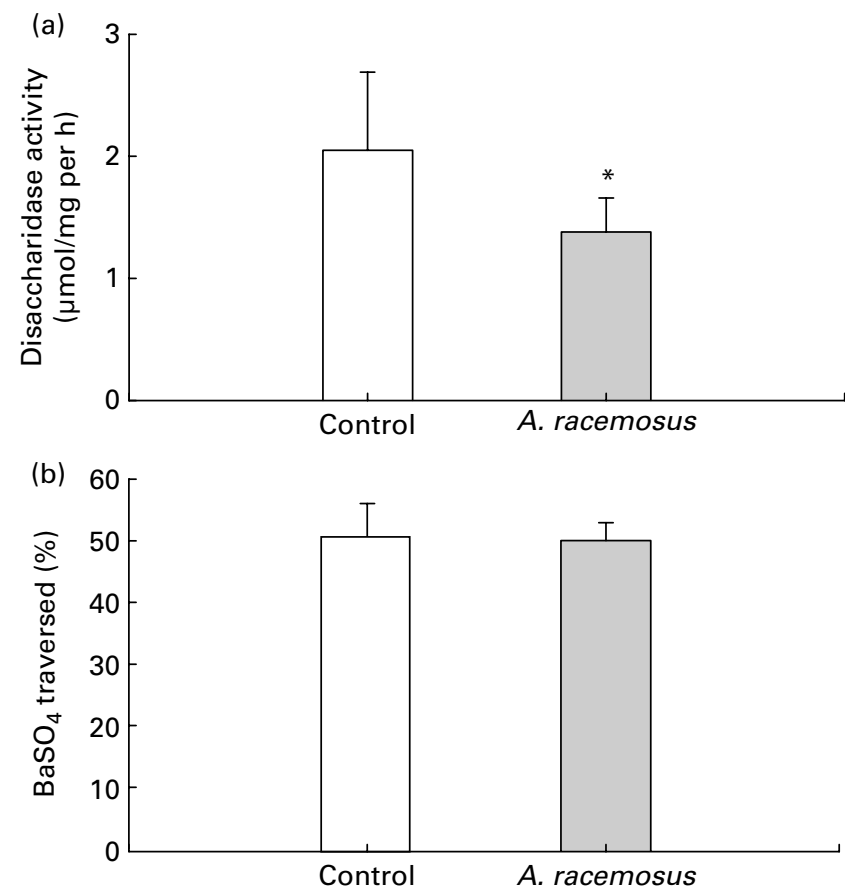

Fig. 5. Effects of ethanol extract of Asparagus racemosus on (a) intestinal disaccharidase activity and (b) gastrointestinal motility (by $\mathrm{BaSO}_{4}$ traversed) in non-diabetic rats. Rats were fasted for $20 \mathrm{~h}$ before the oral administration of ethanol extract of $A$. racemosus $(1.25 \mathrm{~g} / \mathrm{kg}$ body weight). Enzyme activity was determined and $\mathrm{BaSO}_{4}$ administered at $60 \mathrm{~min}$. Motility was measured over the following $15 \mathrm{~min}$. Values are means and standard deviations represented by vertical bars $(n 12)$. ${ }^{*}$ Mean values were significantly different from those of non-diabetic control rats $(P<0.001)$.

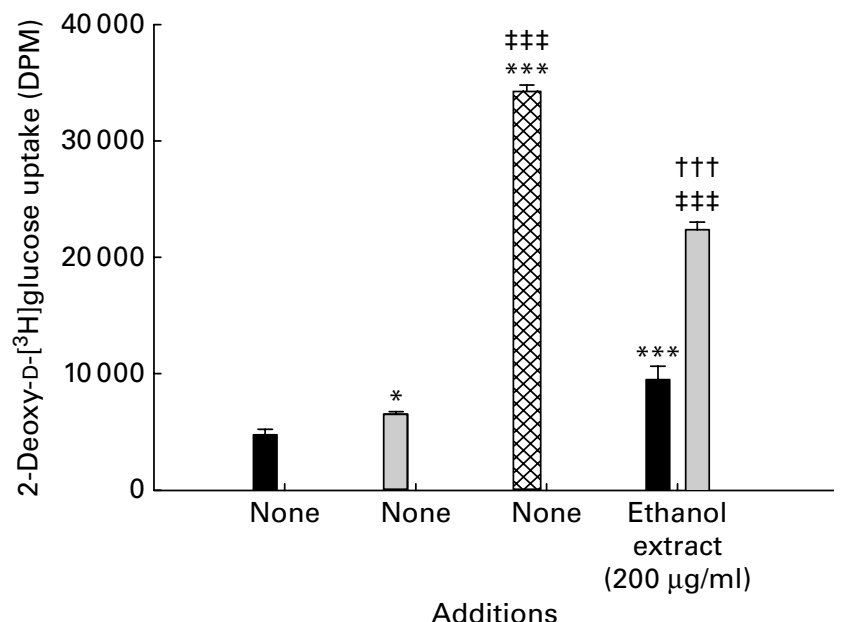

Fig. 6. Effects of ethanol extract of Asparagus racemosus $(200 \mu \mathrm{g} / \mathrm{ml})$ on glucose uptake by 3T3-L1 adipocytes. Values are means and standard deviations represented by vertical bars $(n 6)$. One-way ANOVA was performed and pairwise comparisons were made using Dunnett's test to preserve an overall error rate of $5 \%$. Mean values were significantly different from those of no insulin incubation: ${ }^{\star} P<0.05,{ }^{* \star} P<0.001$. † Mean values were significantly different from those of plant ethanol extract incubation without insulin (घ, $P<0.001)$. ¥Mean values were significantly different from those of $10^{-9} \mathrm{M}$-insulin $(\square)$ alone $(P<0.0001)$. $\otimes, 10^{-6} \mathrm{M}$-insulin. DPM, disintegrations per min.

accompanying elevation of insulin. Further work is required to elucidate the in vivo effects of $A$. rascemosus on glucose uptake, related transporter/enzyme activities or their gene expression in tissues such as liver, fat and muscle. However, the significance of such effect seems less likely, given the absence of the effect of plant extract in type 1 diabetic rats.

In the chronic study, $A$. racemosus extract significantly increased total antioxidant status, which confirms the idea that the extract has potent antioxidant activities ${ }^{(11)}$. Interestingly, liver glycogen content was increased in type 2 diabetic rats compared with the controls after administration for $28 \mathrm{~d}$. This novel finding is possibly due to the stimulation of insulin release from $\beta$-cells plus enhancement of insulin action, thereby improving hepatic glucose uptake.

In conclusion, the present study has shown that in addition to the effects of $A$. racemosus root extract on pancreatic $\beta$-cells ${ }^{(21)}$, antihyperglycaemic activities in normoglycaemic and diabetic animals are associated with decreased intestinal glucose absorption and enhanced tissue glucose utilisation. The identification of active principle(s) from this antidiabetic plant may provide an opportunity to develop new agents for the treatment of type 2 diabetes. Meanwhile, a sound scientific basis appears to exist for the use of $A$. racemosus as a dietary adjuvant for type 2 diabetes.

\section{Acknowledgements}

The present study was supported by the SAAD Trading and Contracting Company and University of Ulster Strategic Research Funding. All authors contributed to the conception and design of the experiments. J. M. A. H., L. A., J. K., M. A. and Y. H. A. A.-W. contributed to the experimental study. P. R. F. and Y. H. A. A.-W. contributed equally to the 
supervision of the study, analysis and preparation of the manuscript. There is no conflict of interest to declare.

\section{References}

1. Nadkharni AK (1976) India Materia Medica. Bombay: Popular Prakashan, pp. 151-155.

2. Chadha YR (1985) The Wealth of India. vol. 1, New Delhi: Publications and Information Directorate, pp. 468-472.

3. Shao Y, Chin C-K, Ho C-T, et al. (1996) Anti-tumour activity of the crude saponins obtained from asparagus. Cancer Lett 104, 31-36.

4. Shimoyamada M, Suzuki M, Sonta H, et al. (1990) Antifungal activity of the saponin fraction obtained from asparagus and its active principle. Agric Biol Chem 54, 2553-2557.

5. Edenharder R (1990) Antimutagenic activity of vegetable and fruit extracts against in-vitro benzo(a)pyrene. $Z$ Gesamte Hyg 36, 144-148.

6. Thatte UM \& Dahanukar SA (1988) Comparative study of immunomodulating activity of Indian medicinal plants, lithium carbonate and glucan. Methods Find Exp Clin Pharmacol 10, 639-644.

7. Rege NN, Nazarreth HM, Isaac A, et al. (1989) Immunotherapeutic modulation of intraperitoneal adhesions by $A$. racemosus. J Postgrad Med 35, 199-203.

8. Dhuley JN (1997) Effect of some Indian herbs on macrophage functions in ochratoxin A treated mice. J Ethnopharmacol 58, 15-20.

9. Balansard S \& Rayband M (1987) Diuretic action of A. racemosus. Crit Rev Soc Biol 126, 954-956.

10. Sharma S, Ramji S, Kumari S, et al. (1996) Randomized controlled trial of $A$. racemosus (Shatavari) as a lactogogue in lactational inadequacy. Indian Padiatr 32, 675-677.

11. Kamat JP, Boloor KK, Devasagayam TPA, et al. (2000) Antioxidant properties of Asparagus racemosus against damage induced by gamma-radiation in rat liver mitochondria. J Ethnopharmacol 71, 425-435.

12. Gang ZZ, Li LZ \& Xian LX (1997) Study on the isolation, purification and antioxidation properties of polysaccharides from Spirulina maxima. Acta Bot Sin 39, 77-81.

13. Liu J, Yeo HC, Doniger SJ, et al. (1997) Assay of aldehydes from lipid peroxidation: gas chromatography-mass spectrometry compared to thioabarbituric acid. Anal Biochem 245, 161-166.

14. Liu SX, Chen Y, Zhou M, et al. (1997) Protective effect of the polysaccharide kreskin on inhibition of lipo-polysaccharide-induced nitric oxide production in macrophages caused by oxidized low-density lipoprotein. Med Sci Res $\mathbf{2 5}$ 507-509.

15. Zeng N, Meng X \& Zhang Y (1997) Studies on the antioxidative effect of constituents of Herba epimedii (ESPS). Zhongguo Zhongyao Zazhi 22, 46-48.

16. Dalvi SS, Nadkarni PM \& Gupta KC (1990) Effect of $A$. racemosus (Shatavari) on gastric emptying time in normal healthy volunteers. J Postgrad Med 36, 91-94.

17. Nwafor PA, Okwuasaba FK \& Binda LG (2000) Antidiarrhoeal and antiulcerogenic effects of methanolic extract of Asparagus pubescens root in rats. J Ethnopharmacol 72, 421-427.

18. Rege NN, Thatte UM \& Dahanukar SA (1999) Adaptogenic properties of six rasayana herbs used in Ayurvedic medicine. Phytother Res 3, 275-291.

19. Rana TS, Singh KK \& Rao RR (1994) Some interesting reports on indigenous herbal remedies for diabetes mellitus from India. In Fourth International Congress Ethnobiology, pp. 17-21. Lukhnow: NBRI.

20. Akhtar MS \& Shah MV (1993) Elemental constituents of antidiabetic screening of a folklore medicinal plant prescription. Ind J Toxicology, Occup Envt Health 2, 46.

21. Hannan JMA, Marenah L, Ali L, et al. (2007) Insulin secretory actions of extracts of Asparagus racemosus root in perfused pancreas, isolated islets and clonal pancreatic $\beta$-cells. J. Endocrinol 192, 159-168.

22. Bonner-Weir S, Trend DF, Honey RN, et al. (1981) Responses of neonatal rat islets to streptozotocin: limited $\beta$-cell regeneration and hyperglycemia. Diabetes 30, 64-69.

23. Goto Y, Yamada K, Ohyama T, et al. (1995) An alpha-glucosidase inhibitor, AO-128, retards carbohydrate absorption in rats and humans. Diabetes Res Clin Pract 28, 81-87.

24. Swintosky JV \& Pogonowskawala E (1982) The in-situ rat gut technique. Pharm Int 3, 163-167.

25. Chatterjee TK (1993) Handbook on Laboratory Mice and Rats, pp. 157. Kolkata, India: Department of Pharmaceutical Technology, Jadavpur University.

26. Frost SC \& Lane MD (1985) Evidence for the involvement of vicinal sulfhydryl groups in insulin-activated hexose transport by 3T3-L1 adipocytes. J Biol Chem 260, 2646-2652.

27. van der Vries J (1954) Two methods for the determination of glycogen in liver. Biochem J 57, 410-416.

28. Flatt PR \& Bailey CJ (1981) Abnormal plasma glucose and insulin response in heterozygous lean $(\mathrm{ob} /+)$ mice. Diabetologia 20, 573-577.

29. Nahar N, Rokeya B, Ali L, et al. (2000) Effects of three medicinal plants on blood glucose levels of non-diabetic and diabetic model rats. Diabetes Res 35, 41-49. 